Western University Scholarship@Western

Chemistry Publications

Chemistry Department

$7-5-2017$

\title{
Self-Healing Polyphosphonium Ionic Networks
}

Elizabeth Gillies

Western University, egillie@uwo.ca

Tyler J. Cuthbert

Western University

Joshua J.Jadischke

Western University

John R. de Bruyn

Western University

Paul J. Ragogna

Western University

See next page for additional authors

Follow this and additional works at: https://ir.lib.uwo.ca/chempub

Part of the Chemistry Commons

Citation of this paper:

Gillies, Elizabeth; Cuthbert, Tyler J.; Jadischke, Joshua J.; de Bruyn, John R.; Ragogna, Paul J.; and Gillies, Elizabeth R., "Self-Healing Polyphosphonium Ionic Networks" (2017). Chemistry Publications. 109.

https://ir.lib.uwo.ca/chempub/109 
Authors

Elizabeth Gillies, Tyler J. Cuthbert, Joshua J. Jadischke, John R. de Bruyn, Paul J. Ragogna, and Elizabeth R. Gillies 


\section{Self-Healing Polyphosphonium Ionic Networks}

Tyler J. Cuthbert, ${ }^{\dagger}$ Josh J. Jadischke, ${ }^{\dagger}$ John R. de Bruyn, ${ }^{\star}$ Paul J. Ragogna, ${ }^{\dagger *}$ and Elizabeth R. Gillies $^{\dagger} *$

${ }^{\dagger}$ Department of Chemistry and the Centre for Advanced Materials and Biomaterials Research The University of Western Ontario, 1151 Richmond St., London, Ontario, Canada, N6A 3B7

Department of Physics and Astronomy and the Centre for Advanced Materials and Biomaterials Research, The University of Western Ontario, 1151 Richmond St. London, Ontario, Canada, N6A 3K7

${ }^{\$}$ Department of Chemical and Biochemical Engineering, The University of Western Ontario, 1151 Richmond St., London, Ontario, Canada, N6A 5B9

*Authors to whom correspondence should be addressed: E-mail: pragogna@uwo.ca, egillie@uwo.ca 


\section{for Table of Contents use only}

Self-Healing Polyphosphonium Ionic Networks

Tyler J. Cuthbert, Josh J. Jadischke, John R. de Bruyn, Paul J. Ragogna,* and Elizabeth R. Gillies*
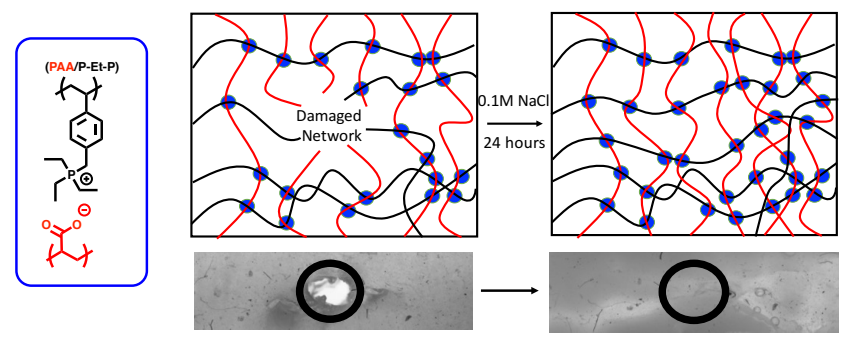


\begin{abstract}
Self healing, ionically crosslinked networks were prepared from poly(acrylic acid) (PAA) and poly(triethyl(4-vinylbenzyl)phosphonium chloride (P-Et-P) and their properties were studied. Three different ratios of PAA/P-Et-P were incorporated into the networks by varying the addition orders of the components. Swelling of the networks increased with increasing $\mathrm{NaCl}$ concentration when they were immersed in aqueous solution. All networks retained their structural integrity in $0.1 \mathrm{M} \mathrm{NaCl}$. Studies of the rheological and tensile properties of the networks swelled in $0.1 \mathrm{M} \mathrm{NaCl}$ showed that PAA $>$ P-Et-P exhibited high elongation and viscoelastic properties suitable for self-healing with a relaxation time of $\sim 30 \mathrm{~s}$, whereas the other networks exhibited predominantly elastic behavior. The moduli were similar to those of soft tissues. Self-healing of PAA >P-Et-P in $0.1 \mathrm{M} \mathrm{NaCl}$ was demonstrated through repair of a 0.5 $\mathrm{mm}$ diameter puncture in the material whereas healing was incomplete for the other networks and also for PAA $>$ P-Et-P in the absence of $\mathrm{NaCl}$. Healing after completely severing a tensile testing sample showed significant recovery of the modulus, strength, and elongation. The properties of these materials and their ability to self-heal in low and physiologically relevant salt concentrations make them promising candidates for a variety of applications, particularly in the biomedical area.
\end{abstract}

\title{
Introduction
}

Self-healing materials are able to renew their structural integrity after damage through dynamic processes, making the prospect of renewable or persistent materials and coatings possible. ${ }^{1-4}$ Self-healing materials are already used in automotive paints and coatings, ${ }^{5}$ and are expected to have much broader applications in the near future, including the stabilization of lithium-ion 
batteries $^{6}$ and in prolonging the lifetime of medical implants such as bone cements and joint and soft tissue replacements. ${ }^{7-9}$ The development of self-healing materials has often involved the incorporation of microcapsules ${ }^{10}$ or vascular networks ${ }^{11}$ that contain additives such as monomers. The healing was then engaged upon damage of the microcapsule container, leakage of the active components, and initiation of the chemical reaction (e.g. polymerization), ultimately filling of the damaged area. A limitation of microcapsule- or vascular-based self-healing networks is the lack of repeatable self-healing in a given location. An alternative is the use of reversibly-crosslinked networks. Cross-linking can involve hydrogen bonding, ${ }^{12}$ coordination of metals, ${ }^{13}$ ionic bonding, ${ }^{14}$ or covalent systems such as disulfide-linkages ${ }^{15,16}$ or Diels-Alder adducts. ${ }^{17}$

The choice of process that mediates healing is important in order to ensure that the network can be repaired in its intended environment. Ionically-crosslinked networks have used two-component polymer blends or interpenetrating polymer networks that contain both polyanions and polycations. ${ }^{18}$ For example, networks comprising poly(allylamine hydrochloride) (PAH) or poly(diallyldimethylammonium chloride) as polycations, coupled with poly(acrylic acid) (PAA) or poly(styrene sulfonate), respectively as polyanions, have been investigated in their hydrated state. ${ }^{18,19}$ These networks involve both physical entanglement of the polymer chains, and chemical crosslinking between ionic groups. Polyelectrolyte crosslinks are favoured due to the entropic release of water and counterions, but still undergo dynamic exchange in the presence of aqueous $\mathrm{NaCl}^{20}$ Over time, the viscoelastic properties of the network, which are a balance between the elastic modulus (solid character) and viscous modulus (fluid character) can allow self-healing at the interface, while still allowing the structural integrity of the materials to be retained. Self-healing of the PAA/PAH networks required high ionic strength (1.0 -2.5 M 
$\mathrm{NaCl}$ ), which may limit their use for in vivo applications. ${ }^{14}$ Furthermore, the requirement for ultracentrifugation to create the PAA/PAH networks may result in challenges for the scaling up of the process. However, the ability of salt water to effectively plasticize polyelectrolyte complexes has been a key enabler for the processing and reprocessing of polyelectrolyte complexes. By analogy with thermoplastics, which can be processed at elevated temperature, these materials have been termed "saloplastics" by Schlenoff. ${ }^{21}$

Phosphonium salts are particularly attractive for materials science applications because of their high thermal and chemical stability as well as their ease of synthesis. ${ }^{22-24}$ Phosphonium cations have different charge densities relative to their ammonium congeners due to the larger size and lower electronegativity of the phosphorus atom, leading to differences in the properties of materials containing phosphonium relative to ammonium centres. Phosphonium-containing macromolecules have been explored in applications such as ionic liquids ${ }^{25}$ and non-viral gene delivery ${ }^{26}$ and they have often been found to exhibit enhanced performance relative to their ammonium analogues. ${ }^{27}$ Of particular interest are the antibacterial properties of phosphoniumbased materials, ${ }^{28-32}$ as they can potentially prevent bacterial infection, when incorporated into medical devices or implants.

Very few examples of phosphonium-based ionically-crosslinked networks have been reported to date. Supramolecular networks have been prepared by combining phosphonium monocations or dications with tetraanions,${ }^{33}$ or with $\mathrm{PAA}^{34}$ as well as by combining a phosphonium polymers with mono- and dicarboxylic acids. ${ }^{35}$ The properties of these different networks could be tuned based on the chemical structures of their components, but their selfhealing was not studied and the limited valency of the interactions would likely prevent them from surviving immersion in aqueous solution. Photoluminescent phosphonium polyelectrolytes 
have been cast in multilayered films with PAA using a layer-by-layer technique. ${ }^{36}$ However, to the best of our knowledge, the combination of polymeric phosphonium cations with polymeric anions to form ionically-crosslinked networks has not been reported. In this context, we report here the combination of polyphosphonium cations with PAA for the preparation of ionicallycrosslinked polymer networks. We demonstrate that the composition and properties of the networks can be regulated according to the network preparation method. The rheology of the networks in $0.1 \mathrm{M} \mathrm{NaCl}$ is described and it is shown that networks with the suitable viscoelastic properties exhibit self-healing capabilities under physiologically relevant salt concentrations.

\section{Experimental}

\section{General materials}

Triethyl(4-vinylbenzyl)phosphonium chloride (Et-P) and tri- $n$-butyl(4-vinylbenzyl)phosphonium chloride (Bu-P) were prepared as previously reported. ${ }^{29}$ Deuterated solvents were purchased from Cambridge Isotopes Laboratories (Tewksbury, MA, USA). Other solvents were purchased from Caledon Laboratory Chemicals (Georgetown, ON, Canada). All solvents used for polymerizations were degassed before use by three freeze-dry-thaw cycles and kept under an $\mathrm{N}_{2}$ atmosphere. PAA ( $25 \mathrm{wt} \%$ in water, sold as $240 \mathrm{~kg} \mathrm{~mol}^{-1}$ ) was purchased from VWR (Mississauga, ON, Canada). Phosphines were donated by Solvay-Cytec (Niagara Falls, ON, Canada) and used as received.

\section{General methods}


Differential scanning calorimetry (DSC) was performed on a DSC Q20 from TA Instruments (Waters, New Castle, DE, USA) at a ramp rate of $10{ }^{\circ} \mathrm{C} / \mathrm{min}$ under an $\mathrm{N}_{2}$ atmosphere in an aluminum Tzero ${ }^{\mathrm{TM}}$ pan using 5-10 $\mathrm{mg}$ of sample. Thermogravimetric analysis (TGA) was completed on a Q600 SDT TA Instrument and analyzed at a ramp rate of $10^{\circ} \mathrm{C} \mathrm{min}^{-1}$ up to $600{ }^{\circ} \mathrm{C}$ using a ceramic pan with $2-4 \mathrm{mg}$ of sample. Nuclear magnetic resonance spectroscopy (NMR) was performed on a Varian Inova $400 \mathrm{MHz}$ Spectrometer. ${ }^{1} \mathrm{H}$ NMR chemical shifts ( $\delta$ ) relative to tetramethylsilane were referenced using residual solvent peaks $\left(\mathrm{CDCl}_{3}: 7.26 \mathrm{ppm}\right.$, $\left.\mathrm{CD}_{3} \mathrm{OD}: 3.31 \mathrm{ppm}\right) .{ }^{31} \mathrm{P}$ NMR was externally referenced to $\mathrm{H}_{3} \mathrm{PO}_{4}(\delta=0)$. Size exclusion chromatography (SEC) of the phosphonium polymers was performed using a Malvern VISCOTEK GPCmax instrument equipped with a VISCOTEK VE 3580 RI Detector and two Inert series columns (P101609 and Q10183) at a constant temperature of $50{ }^{\circ} \mathrm{C}$. The eluent was $0.4 \mathrm{M}$ tetrabutylammonium triflate in $N, N$-dimethylformamide (DMF) with a flow rate of $1 \mathrm{~mL}$ $\min ^{-1}$. Calibration was performed using poly(methyl methacrylate) (PMMA) standards to determine the number-average molar mass $\left(\mathrm{M}_{\mathrm{n}}\right)$ and dispersity $(\nexists)$. SEC of PAA was performed using a Waters 2695 Separations Module equipped with a Waters 2414 refractive index detector, PL Aquagel-OH $8 \mu \mathrm{m} 30,40$, and 50 columns and a PL Aquagel-OH guard column, using $\mathrm{H}_{2} \mathrm{O}$ with $0.1 \mathrm{M} \mathrm{NaN}_{3}$ with a flow rate of $1 \mathrm{~mL} \mathrm{~min}^{-1}$. Calibration was performed using PEO standards. Scanning electron microscopy with energy dispersive X-ray spectroscopy (SEMEDX) was performed using a Hitachi S-3400N Variable Pressure Microscope with a Turbomolecular pump. Samples were analyzed at an accelerating voltage of $20 \mathrm{kV}$, and analyzed by EDX analysis using an INCA EDAX system and software. Samples were cut into pieces approximately $1 \mathrm{~mm} \times 1 \mathrm{~mm}$ with a thickness of $1 \mathrm{~mm}$ and dried overnight in a vacuum oven, then mounted on carbon tabs and coated with $5 \mathrm{~nm}$ of osmium prior to analysis. 


\section{Synthesis of poly(triethyl(4-vinylbenzyl)phosphonium chloride (P-Et-P)}

Et-P $^{29}$ (26.1 g, $\left.96.6 \mathrm{mmol}\right)$, azobisisobutyronitrile (AIBN) (20 mg, $0.12 \mathrm{mmol}$ ) and dimethyl sulfoxide (DMSO) $(130 \mathrm{~mL})$ were combined in a round bottom flask with a stir bar and the flask was sealed with a rubber septum and Teflon tape. $\mathrm{N}_{2}$ was bubbled through the solution using a needle with stirring at room temperature for $30 \mathrm{~min}$ to degas the reaction mixture. The reaction mixture was then heated at $80{ }^{\circ} \mathrm{C}$ for $16 \mathrm{~h}$. The solvent was then removed in vacuo at $100{ }^{\circ} \mathrm{C}$ and the polymer was purified by precipitation from 2-propanol into THF twice, yielding a white solid. Yield $=13.6 \mathrm{~g}, 52 \% ;{ }^{1} \mathrm{H}$ NMR $\left(400 \mathrm{MHz}, \mathrm{D}_{2} \mathrm{O}\right): \delta=6.99(\mathrm{br} \mathrm{s}, 2 \mathrm{H}, \mathrm{Ar}-\mathrm{H}), 6.33$ (br s, $2 \mathrm{H}$, Ar-H), 3.50 (br s, 2H, Ar- $\mathrm{CH}_{2} \mathrm{P}$ ), 1.93 (s, $6 \mathrm{H}, \mathrm{CH}_{2} \mathrm{P}$ and backbone $\mathrm{CH}$ ), 1.34 (br s, 2H, backbone $\left.\mathrm{CH}_{2}\right), 0.86\left(\mathrm{~s}, 9 \mathrm{H}, \mathrm{CH}_{3}\right) ;{ }^{31} \mathrm{P}-\mathrm{NMR}\left(161 \mathrm{MHz}, \mathrm{D}_{2} \mathrm{O}, \delta\right): 36.8(\mathrm{~s}) . \mathrm{T}_{\mathrm{g}}=225^{\circ} \mathrm{C} ; \mathrm{T}_{\mathrm{o}}=335^{\circ} \mathrm{C}$; SEC: $\mathrm{M}_{\mathrm{n}}=240 \mathrm{~kg} \mathrm{~mol}^{-1} ; \oslash=2.4$.

\section{Synthesis of poly(tri-n-butyl(4-vinlbenzyl)phosphonium chloride (P-Bu-P)}

Bu-P ${ }^{29}(1.05 \mathrm{~g}, 2.02 \mathrm{mmol})$, AIBN $(1.0 \mathrm{mg}, 6.1 \mu \mathrm{mol})$ and $\mathrm{CH}_{3} \mathrm{CN}(7 \mathrm{~mL})$ were combined in a Schlenk flask with a stir bar and a Suba Seal septum. The solution was degassed with a flow of $\mathrm{N}_{2}$ through the solution using a needle at $0{ }^{\circ} \mathrm{C}$ for $30 \mathrm{~min}$. The resulting mixture was then heated at $80{ }^{\circ} \mathrm{C}$ for $16 \mathrm{~h}$. The solvent was removed in vacuo, and the resulting solid was dissolved in minimal $\mathrm{CH}_{2} \mathrm{Cl}_{2}(\sim 3 \mathrm{~mL})$, and precipitated by the addition of tetrahydrofuran $(50 \mathrm{~mL})$ with vigorous stirring. The precipitation procedure was repeated, resulting in a white solid. Yield $=$ $0.96 \mathrm{~g}, 91 \% .{ }^{1} \mathrm{H}$ NMR (400 MHz, $\left.\mathrm{CDCl}_{3}\right)^{*}: \delta=7.35$ (broad, Ar-H), 6.29 (broad, Ar-H), 4.37 (broad, Ar- $\left.-\mathrm{CH}_{2} \mathrm{P}\right), 2.36$ (broad, P- $\left.\underline{\mathrm{H}}_{2}-\left(\mathrm{CH}_{2}\right)_{2}-\mathrm{CH}_{3}\right), 1.95$ (broad, backbone $\mathrm{CH}$ ), 1.39 (broad, P- 
$\mathrm{CH}_{2}-\left(\underline{\mathrm{C}}_{2}\right)_{2}-\mathrm{CH}_{3}$ and backbone $\left.\mathrm{CH}_{2}\right), 0.84$ (broad, $\left.\underline{\mathrm{CH}}_{3}\right) ;{ }^{31} \mathrm{P}\left\{{ }^{1} \mathrm{H}\right\} \mathrm{NMR}\left(161.82 \mathrm{MHz}, \mathrm{CDCl}_{3}\right.$,

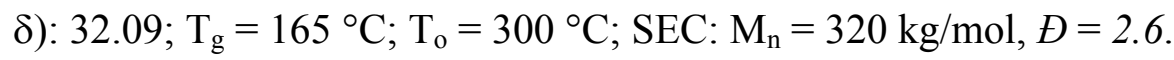

*Peaks corresponding to the styrenic backbone and adjacent to the phosphonium were very broad and did not integrate accurately (at ${ }^{1} \mathrm{H}$ NMR delay time set to $10 \mathrm{~s}$ ), likely due to slow proton relaxation, so peak integrations are not included.

\section{Preparation of ionic networks}

The polyphosphonium and PAA were dissolved separately in deionized (DI) water (pH 8), at concentrations of $0.1 \mathrm{M}$ in terms of the ions. With vigorous stirring, the solutions were combined slowly in a large beaker, adding one solution to the other to produce non-stoichiometric polymer networks PAA $>$ P-Et-P or PAA $<$ P-Et-P, or both solutions simultaneously into a new beaker to produce the network PAA $\approx$ P-Et-P. The liquid was decanted and the network was then soaked in $0.25 \mathrm{M} \mathrm{NaCl}$ for $2 \mathrm{~h}$. The resulting swelled solid was manually combined into a sphere and then immersed in $0.25 \mathrm{M} \mathrm{NaCl}$ for $2 \mathrm{~h}$. The polymer network was then pressed between Teflon sheets to $1-4 \mathrm{~mm}$ thickness using a melt press at $50^{\circ} \mathrm{C}$ for one hour. The polymer network sheets were then separated from the Teflon. Often, the networks adhered to the Teflon sheets and were placed in a freezer overnight to allow for easier removal. Finally, the networks were conditioned in $0.1 \mathrm{M} \mathrm{NaCl}$ overnight before any mechanical testing or healing experiment.

\section{Determination of swelling}

Freshly pressed sheets were cut into $0.5 \mathrm{~cm}$ x $0.5 \mathrm{~cm}$ squares $(1 \mathrm{~mm}$ thickness $)$ and were soaked in DI water overnight to ensure removal of all residual $\mathrm{NaCl}$ ions. The networks were then dried in vacuo overnight. The samples were then place in the appropriate concentration of $\mathrm{NaCl}$ 
solutions for 24 hours. The solutions were decanted, and the remaining solid was dried by dabbing with a Kimwipe and then weighed. Triplicate samples were evaluated. Mass swelling \% was calculated by the following equation:

$$
\text { Swelling } \%=100 \% \times \frac{\text { mass of swelled network }- \text { mass of dried network }}{\text { mass of dried network }}
$$

\section{Rheology}

Rheological measurements were carried out at $21^{\circ} \mathrm{C}$ on an AR1500ex stress-controlled rotational rheometer (TA Instruments) with a $2.5 \mathrm{~cm}$ diameter parallel-plate tool. Smallamplitude oscillatory shear measurements were performed over the frequency range 0.01-100 rad

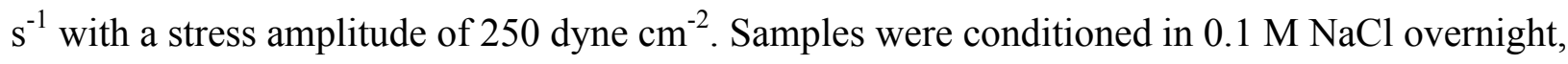
and cut into disks with a $3 \mathrm{~cm}$ diameter and thickness of $\sim 1 \mathrm{~mm}$, measured using a Vernier caliper. The gap between the plates of the rheometer tool was initially set equal to the measured thickness of the gel sample, then the tool was lowered to decrease the gap by $20 \mu \mathrm{m}$. The sample was then allowed to relax for a few minutes before measurements were started. Samples were run in duplicate.

\section{Tensile testing}

Tensile measurements were conducted on an Instron 5943 with serrated callipers using to a closing pressure of 10 PSI and a strain speed of $500 \mathrm{~mm} \mathrm{~min}^{-1}$. Sheets of the networks (preconditioned in $0.1 \mathrm{M} \mathrm{NaCl}$ ) with 1-4 mm thickness, measured accurately with a caliper, were cut using a dog-bone-shaped cutter according to ASTM standard D638-14 Type V. Triplicate samples of each network were evaluated. 


\section{Healing experiments}

For the puncture tests, networks were punctured with an 18-gauge needle and the material was removed to create a $0.5 \mathrm{~mm}$ diameter hole. Damaged networks were then soaked in $0.1 \mathrm{M} \mathrm{NaCl}$ or deionized water and imaged using a stereomicroscope at 20x magnification in transmission mode at $\mathrm{t}=0 \mathrm{~h}, 1 \mathrm{~h}, 2 \mathrm{~h}, 3 \mathrm{~h}, 6 \mathrm{~h}, 11 \mathrm{~h}$, and $24 \mathrm{~h}$. For the tensile testing after healing, the dog bone shaped network samples were cut in half with a scalpel, manually pressed back together for $1 \mathrm{~min}$, and then incubated in $0.1 \mathrm{M} \mathrm{NaCl}$ for $24 \mathrm{~h}$. Tensile testing was then performed as described above. The experiment was performed in triplicate.

\section{Results and Discussion}

\section{Synthesis and characterization of the polyphosphonium}

Et-P and Bu-P were prepared as previously reported. ${ }^{29}$ As shown in Scheme 1, polymerization of these monomers was then performed using AIBN in DMSO at $80{ }^{\circ} \mathrm{C}$ to afford P-Et-P and PBu-P. A reaction time of $18 \mathrm{~h}$ resulted in greater than $80 \%$ monomer conversion. Complete conversion was not observed, even at longer polymerization times and therefore, purification of the final product from the remaining monomer was required. Two precipitations from 2-propanol into tetrahydrofuran (THF) yielded the polymers as white powders. The ${ }^{1} \mathrm{H}$ NMR spectra of the polyphosphonium salts exhibited broad signals that were consistent with the proposed structures (Figure S1-S2) and the corresponding ${ }^{31} \mathrm{P}\left\{{ }^{1} \mathrm{H}\right\}$ NMR spectra had single broad peaks characteristic of the phosphonium ions (Figure S3-S4). Thermogravimetric analysis showed that P-Et-P and P-Bu-P had onset decomposition temperatures $\left(\mathrm{T}_{\mathrm{o}}\right)$ of $335^{\circ} \mathrm{C}$ and $300^{\circ} \mathrm{C}$, 
respectively and glass transition temperatures $\left(\mathrm{T}_{\mathrm{g}}\right)$ of $225^{\circ} \mathrm{C}$ and $165^{\circ} \mathrm{C}$, respectively (Figures S5-S8).

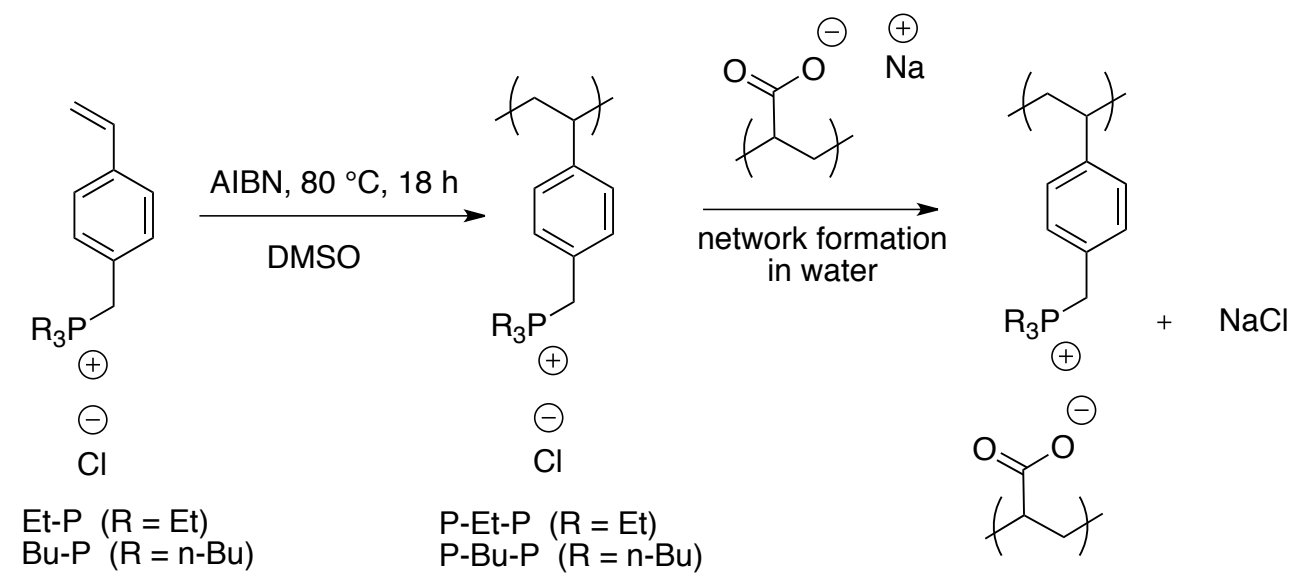

Scheme 1. Synthesis of the polyphosphoniums and their combination with PAA to form ion pairs.

SEC was performed in DMF containing 0.4 M tetrabutylammonium triflate. Relative to PMMA standards, P-Et-P and P-Bu-P had $\mathrm{M}_{\mathrm{n}}$ values of $240 \mathrm{~kg} \mathrm{~mol}^{-1}$ and $320 \mathrm{~kg} \mathrm{~mol}^{-1}$, respectively and $Ð$ values of 2.5 and 2.6, respectively (Figure S9-S10). Controlled radical polymerization methods such as reversible addition-fragmentation chain-transfer polymerization (RAFT) were also explored, as these have previously been used for the preparation of polyphosphonium materials. ${ }^{29}$ However, it was found that the conventional free radical polymerization could more easily provide high molar mass polymers on a large scale and any potential advantages from having a polyphosphonium with lower $Ð$ could be offset by the relatively broad $Ð$ of the commercial PAA. Although the PAA had a reported $\mathrm{M}_{\mathrm{n}}$ of $240 \mathrm{~kg} \mathrm{~mol}{ }^{-}$ ${ }^{1}$, aqueous SEC analysis revealed a bimodal distribution with $\mathrm{M}_{\mathrm{n}}$ values of $80 \mathrm{~kg} \mathrm{~mol}^{-1}(\bigoplus=$ $1.05)$ and $2 \mathrm{~kg} \mathrm{~mol}^{-1}(\bigoplus=1.62)$ relative to poly(ethylene oxide) (PEO) standards (Figure S11). The large molar mass dispersities of the polymers may influence the self-healing properties of the resulting networks, due to the effects of different polymer chain lengths on chain mobility 
and relaxation at the site of healing. Although it will not be explored in the current work, previous research has suggested that the effects of lower molar mass chains may facilitate chain mobility, which is important for self-healing. ${ }^{37}$

\section{Preparation and characterization of ionic networks}

To prepare the networks from PAA and P-Et-P, the polymers were separately dissolved in $0.1 \mathrm{M}$ aqueous $\mathrm{NaCl}$ at a concentration of $0.1 \mathrm{M}$ (of carboxylate or phosphonium content) and the $\mathrm{pH}$ was adjusted to 8.0 using $\mathrm{NaOH}$. Equivalent volumes of each polyion solution were then combined to yield an insoluble polymer network. Excess liquid was decanted, the material was swelled in $0.25 \mathrm{M} \mathrm{NaCl}$, and then manually worked into a sphere. The network could then be pressed at $50^{\circ} \mathrm{C}$ for $1 \mathrm{~h}$ between Teflon sheets to afford a sheet of material. The sheet was then immersed in $0.1 \mathrm{M} \mathrm{NaCl}$ to equilibrate the system before cutting it to the desired shape. It is noteworthy that no centrifugation and or high $\mathrm{NaCl}$ concentrations were required in either the network preparation or in its isolation. PAA/P-Bu-P networks were also prepared, but these networks swelled extensively, exhibited predominantly fluid-like behaviour, and consequently could not be processed for further study. This can likely be attributed to the steric bulk and/or the hydrophobicity of the butyl groups mitigating the extent of ionic crosslinking. All experiments in the subsequent discussion focus on the PAA/P-Et-P networks.

It has been established that the order of addition of the polyions to yield the ionically cross-linked network affects the ratio of the components within the network, even when combining stoichiometrically equivalent amounts of each ion. ${ }^{19}$ Therefore, in the current work, three networks with different ratios of PAA and P-Et-P were prepared using different addition protocols. To obtain more carboxylate anions relative to phosphonium cations in the networks 
(PAA >P-Et-P), the P-Et-P solution was added to the PAA solution by slow, dropwise addition (Figure 1a). Networks with approximately equal numbers of carboxylate anions and phosphonium cations (PAA $\approx$ P-Et-P) were produced by fast, simultaneous addition of the two solutions (Figure 1b). Networks with more phosphonium cations than carboxylate anions $(\mathbf{P A A}<\mathbf{P}-\mathbf{E t}-\mathbf{P})$ were prepared by slow, dropwise addition of the PAA solution into a P-Et-P solution (Figure 1c). The difference in component ratios from these different methods arises from ionic bonding between the polyanion/cation pair occurring with an excess of one component in solution. Polymer chain overlap occurs during the initial crosslinking, which inhibits polymer chain matching. ${ }^{19}$
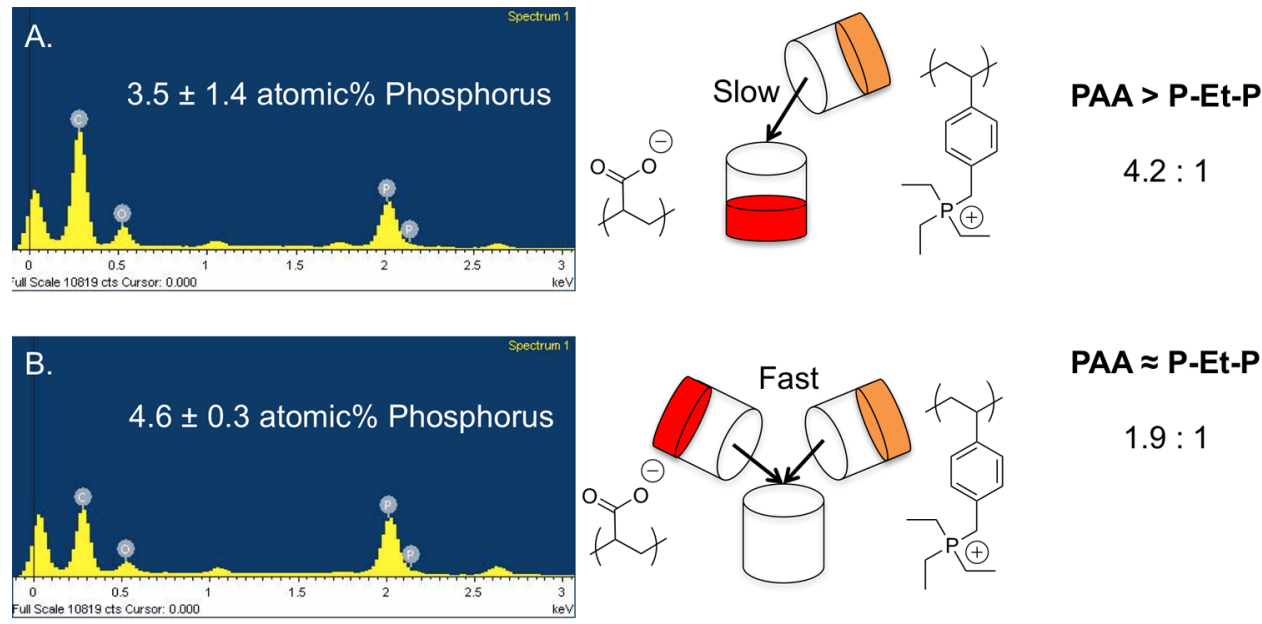

$\mathrm{PAA} \approx \mathrm{P}-\mathrm{Et}-\mathrm{P}$

$1.9: 1$
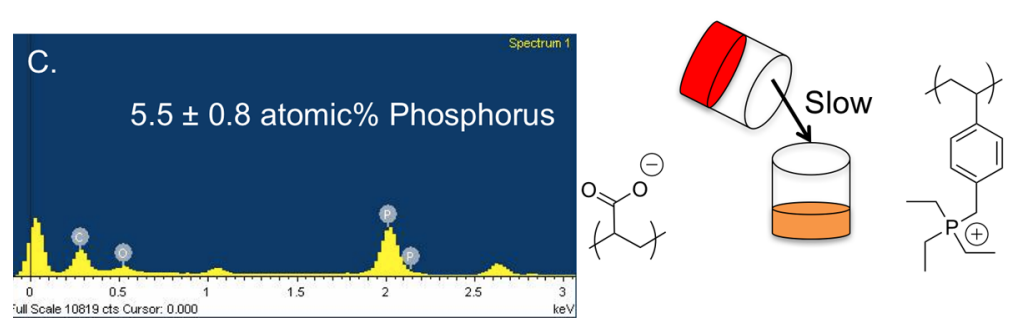

PAA $<$ P-Et-P

$0.73: 1$

Figure 1. SEM-EDX analyses of ionic networks: A) PAA $>$ P-Et-P, B) PAA $\approx$ P-Et-P, and C) $\mathbf{P A A}<\mathbf{P}-\mathbf{E t}-\mathbf{P}$ along with schematics illustrating their methods of preparation and corresponding ratios of carboxylate:phosphonium calculated from the atomic $\%$ of $\mathrm{P}$ relative to $\mathrm{C}$. 
Thermal analysis of the PAA/P-Et-P networks after incubation in pure water to remove salts, followed by drying, showed that they exhibited a two-stage decomposition with the first stage having $\mathrm{T}_{\mathrm{o}} \sim 200{ }^{\circ} \mathrm{C}$, corresponding to decomposition of the PAA, and the second stage having $\mathrm{T}_{\mathrm{o}} \sim 350{ }^{\circ} \mathrm{C}$, corresponding to the P-Et-P (Figure S12). This indicates that the thermal stability is limited by the PAA rather than the polyphosphonium. The DSC thermogram showed a weak transition at $\left(106^{\circ} \mathrm{C}\right)$, and is likely a result of discrete domains of PAA within the bulk material (Figure S13). In contrast, networks composed of phosphonium dications and PAA had $\mathrm{T}_{\mathrm{g}}$ values ranging from -40 to $8^{\circ} \mathrm{C},{ }^{34}$ showing the importance of the polyphosphonium cation in determining the thermal properties of the network.

PAA $>$ P-Et-P, PAA $\approx$ P-Et-P, and PAA $<$ P-Et-P networks were also analyzed after desalting and drying using SEM-EDX to determine the relative amounts of carbon and phosphorus in the networks. Phosphorus atomic \% values (relative to carbon) for PAA $>$ P-Et-P, $\mathbf{P A A} \approx \mathbf{P}-\mathbf{E t}-\mathbf{P}$, and PAA $<$ P-Et-P were measured to be $3.5 \pm 1.4,4.6 \pm 0.3$, and $5.5 \pm 0.8$, corresponding to carboxylate:phosphonium ratios of 4.2:1, 1.9:1, and $0.73: 1$, respectively (calculation in supplementary information). ${ }^{31} \mathrm{P}\left\{{ }^{1} \mathrm{H}\right\}$ NMR spectroscopy with triethylphosphine oxide as an internal standard was also performed on the networks that were swelled with saturated $\mathrm{NaCl}$ solution. Although the results cannot be used to determine the exact phosphonium content due to differences between the crosslink densities and swelling properties of the three networks, the data indicate a trend of increasing phosphonium content for PAA $>\mathbf{P}$ Et-P, PAA $\approx$ P-Et-P, and PAA $<$ P-Et-P, which is in agreement with the SEM-EDX analysis (Figure S14). It is reported that 1:1 stoichiometric equivalents of carboxylate and ammonium could be incorporated into ionic networks by the simultaneous addition of the two polymers. ${ }^{19}$ 
We hypothesize that the tendency towards higher PAA content for the current system is related to the larger size of the phosphonium monomers as compared to the previously investigated ammonium monomers.

To understand how the ionic crosslinks behaved as a function of the ionic strength of the solution, an experiment was performed to determine the effect of $\mathrm{NaCl}$ concentration on the swelling and structural integrity of the networks. The networks were dried, weighed, then immersed in $0 \mathrm{M}, 0.1 \mathrm{M}, 0.25 \mathrm{M}$, and $0.5 \mathrm{M}$ aqueous $\mathrm{NaCl}$ solutions and reweighed. As shown in Figure 2, in pure water and $0.1 \mathrm{M} \mathrm{NaCl}$, all networks swelled resulting in mass increases to $\sim 200 \%$ of their initial masses. At $0.1 \mathrm{M} \mathrm{NaCl}$, the structural integrity of the networks was retained for at least 2 months. At $0.25 \mathrm{M} \mathrm{NaCl}, \mathbf{P A A} \approx \mathbf{P}-\mathbf{E t}-\mathbf{P}$ and $\mathbf{P A A}<\mathbf{P}-$ Et-P did not swell further, whereas PAA>P-Et-P swelled to almost $400 \%$ its initial mass. At $0.5 \mathrm{M} \mathrm{NaCl}$, all three networks exhibited increased swelling, with the degree of swelling increasing with the carboxylate content of the networks. At this concentration the structural integrity of the networks decreased, as they were observed to flow and were mechanically very weak. On the basis of these results, a salt concentration of $0.1 \mathrm{M} \mathrm{NaCl}$ was selected for more detailed experiments on self-healing as well as rheological and mechanical properties. 


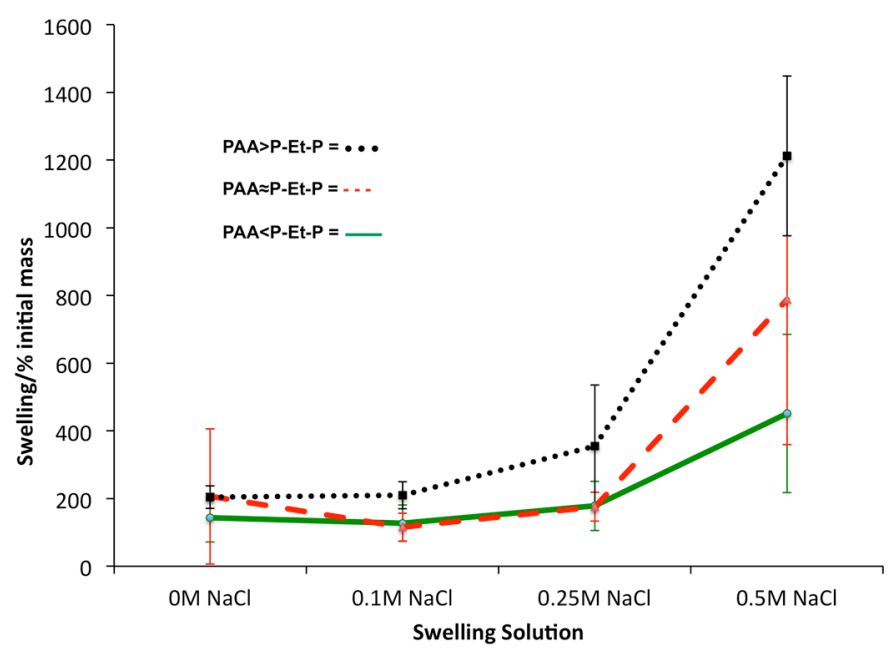

Figure 2. Swelling of polymer networks at different $\mathrm{NaCl}$ concentrations, as indicated by their mass increase upon adsorption of the aqueous solution (\% initial mass).

\section{Rheological and mechanical properties}

Rheological measurements of dynamic polymer networks provide information on the mechanisms and time scales for network relaxation, and can help to determine if the networks have the properties required for self-healing behavior. Measurements of the elastic $\left(G^{\prime}\right)$ and viscous $\left(\mathrm{G}^{\prime \prime}\right)$ moduli of the networks, preconditioned in $0.1 \mathrm{M} \mathrm{NaCl}$, for frequencies from 0.01 to $100 \mathrm{rad} \mathrm{s}^{-1}$ are shown in Figure 3. The moduli of the PAA $>\mathbf{P}-\mathbf{E t}-\mathbf{P}$ network were similar in magnitude, with G' slightly larger than G', at high frequencies. The moduli cross over at a frequency $\omega_{\mathrm{c}} \approx 0.03 \mathrm{rad} \mathrm{s}^{-1}$, corresponding to a relaxation time of $1 / \omega_{\mathrm{c}} \sim 30 \mathrm{~s}$. The PAA $\approx \mathbf{P}-\mathbf{E t}-\mathbf{P}$ network had moduli approximately an order of magnitude higher than those of the PAA $>$ P-Et-P network, and a crossover frequency lower than the minimum frequency studied, implying a relaxation time greater than 100 s. The moduli for the PAA $\approx \mathbf{P}-\mathbf{E t}-\mathbf{P}$ networks showed a similar frequency dependence to PAA $>\mathbf{P}-\mathbf{E t}-\mathbf{P}$ at frequencies less than $0.1 \mathrm{rad} \mathrm{s}^{-1}$, but tended to flatten out at higher frequencies as the PAA $\approx$ P-Et-P network entered into a rubbery plateau. 


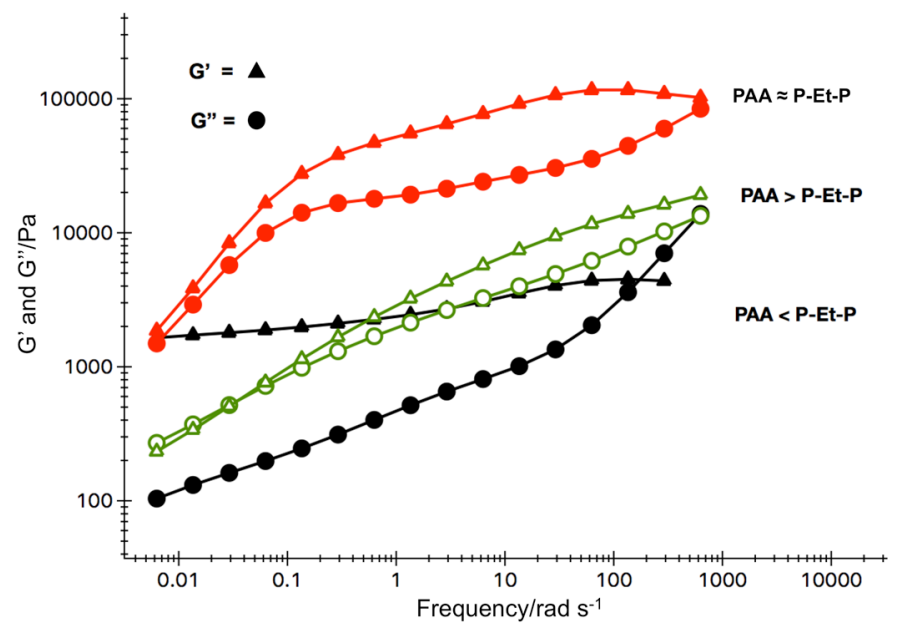

Figure 3. Comparison of the rheology frequency sweep data of PAA/P-Et-P networks preconditions in $0.1 \mathrm{M} \mathrm{NaCl}$.

The elastic modulus of the PAA $<$ P-Et-P networks was strongly dominant at frequencies up to $100 \mathrm{rad} \mathrm{s}^{-1}$ (Figure 3), indicating extremely slow chain-scale relaxation. The viscous modulus increased with increasing frequency however, and became greater than the elastic modulus at about $200 \mathrm{rad} \mathrm{s}^{-1}$, suggesting that relaxation of short chain segments is the dominant relaxation process in this network. The relatively constant elastic modulus and low viscous modulus is typical of gels, and has been observed for crosslinked networks that exhibit no relaxation by reptation. ${ }^{38}$ This could indicate low mobility of P-Et-P in these networks due to its high molar mass and high $\mathrm{T}_{\mathrm{g}}$. In contrast, the networks containing more PAA may be more mobile due to the lower molar mass of the PAA.

In agreement with the current results, PAA/PAH networks with a stoichiometric balance of charges also gave the stiffest networks. This was attributed to a higher density of crosslinking compared other compositions. ${ }^{19}$ The elastic-viscous crossover frequency was lower for the stoichiometric PAA/PAH networks than for non-stoichiometric networks, meaning that the 
relaxation time was longer. ${ }^{19}$ The behavior observed in our PAA/P-Et-P networks is different, with the relaxation time increasing as the fraction of PAA decreased. In general the viscous and elastic moduli of our networks swelled in $0.1 \mathrm{M} \mathrm{NaCl}$ were similar in magnitude to those of networks prepared from PAA and phosphonium dications in the dry state. ${ }^{34}$ This illustrates the importance of highly-multivalent ionic interactions in determining the rheological properties of the networks. The fast relaxation of the PAA $>$ P-Et-P networks suggest that they are good candidates for self-healing, whereas the networks with higher P-Et-P content may be better suited for other applications such as stimuli-responsive gels for drug delivery or degradable polymer networks. ${ }^{39}$ Thus, further discussion will focus on the PAA $>$ P-Et-P network with additional information on the other networks included in the supporting information (Figure S15, Table S1).

To further evaluate the mechanical properties of the PAA $>$ P-Et-P networks, tensile testing was performed. This network, preconditioned in $0.1 \mathrm{M} \mathrm{NaCl}$, exhibited a high elongation at break of $1330 \%$, but underwent plastic deformation and started necking before breakage (Table 1, Figure 4). The ultimate tensile strength was $33 \pm 9 \mathrm{KPa}$. The measured Young's modulus was $15 \pm 2 \mathrm{KPa}$, which is comparable to some soft tissues and organs such as the human aorta. ${ }^{40}$ Overall, the phosphonium-based material has an elongation of similar magnitude but significantly lower Young's modulus and ultimate tensile strength than the analogous PAA/PAH network. ${ }^{14}$ 


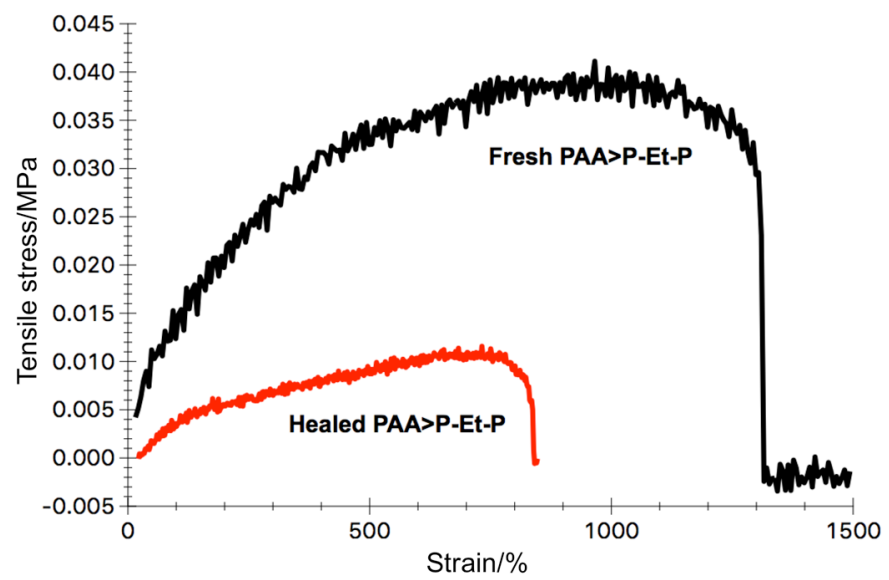

Figure 4. Tensile properties of PAA/P-Et-P networks preconditioned in $0.1 \mathrm{M} \mathrm{NaCl}$ prior to and after healing in $0.1 \mathrm{M} \mathrm{NaCl}$ following complete severing of the sample. A dog bone structure was used in accordance with ASTM D638 14.

Table 1. Summary of the tensile properties of PAA $>$ P-Et-P networks preconditioned in $0.1 \mathrm{M}$ $\mathrm{NaCl}$.

\begin{tabular}{|c|c|c|c|}
\hline Network & $\begin{array}{l}\text { Young's Modulus } \\
(\mathrm{KPa})\end{array}$ & $\begin{array}{l}\text { Elongation at } \\
\text { break \% }\end{array}$ & $\begin{array}{l}\text { Ultimate tensile stress } \\
(\mathrm{KPa})\end{array}$ \\
\hline PAA $>$ P-Et-P & $15 \pm 2$ & $1330 \pm 250$ & $33 \pm 9$ \\
\hline $\begin{array}{l}\text { PAA }>\text { P-Et-P } \\
\text { (after severing and } \\
\text { healing) }\end{array}$ & $5 \pm 3$ & $740 \pm 160$ & $10 \pm 1$ \\
\hline
\end{tabular}

\section{Self-healing}

The ability of PAA $>$ P-Et-P networks to self-heal was first studied qualitatively. Networks of $\sim 4$ $\mathrm{mm}$ thickness were damaged by boring a $\sim 0.5 \mathrm{~mm}$ diameter hole. The networks were then 
incubated in either $0.1 \mathrm{M} \mathrm{NaCl}$ or pure water. The hole in the network in $0.1 \mathrm{M} \mathrm{NaCl}$ healed completely over $24 \mathrm{~h}$ and no significant healing was observed in pure water (Figure 5). This is consistent with ionic exchange being required to achieve dynamic properties in the network. Consistent with their rheological properties, incomplete healing was observed for PAA $<$ P-Et-P and PAA $\approx$ P-Et-P networks under these conditions (Figure S16), and under higher salt concentrations the networks lost their structural integrity as noted above.

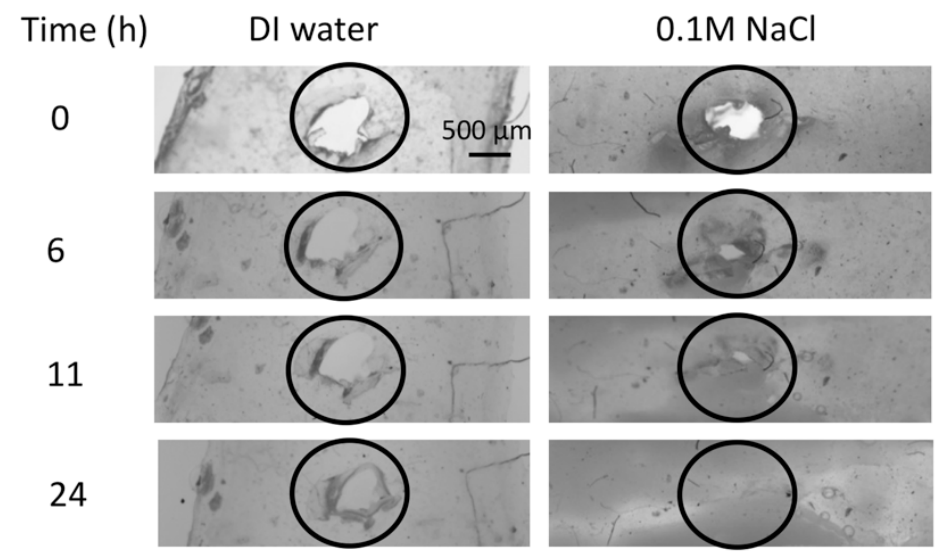

Figure 5. Digital images of a PAA $>$ P-Et-P network damaged by a $0.5 \mathrm{~mm}$ diameter hole selfhealing over $24 \mathrm{~h}$ in $0.1 \mathrm{M} \mathrm{NaCl}$ (right-hand column) versus a similar network in pure water (left-hand column), where no significant healing was observed.

To probe more quantitatively the self-healing capabilities of PAA $>\mathbf{P}-\mathbf{E t}-\mathbf{P}$, a sample of the network was completely severed, pressed together manually for $1 \mathrm{~min}$, incubated for $24 \mathrm{~h}$ in $0.1 \mathrm{M} \mathrm{NaCl}$, and then subjected to tensile testing. This test can provide information on the ability of the network to repair extensive damage across a large area. As shown in Figure 4 and Table 1, the healed networks recovered $\sim 55 \%$ of their initial elongation at break and $\sim 33 \%$ of their initial Young's modulus and ultimate tensile strength. Based on previous work with PAA/PAH 
networks, ${ }^{14}$ the ability of PAA $>$ P-Et-P networks to recover their original tensile properties could likely be enhanced by increasing the time during which the severed portions were pressed together or by tuning their chemical structures. However, the ability of the current networks to heal under low salt concentrations is a significant advantage, as mending did not occur at $0.15 \mathrm{M}$ for the PAA/PAH system and much higher salt concentrations $(\geq 1 \mathrm{M})$ were required to achieve significant recovery of tensile properties. ${ }^{14}$

The mechanism of healing is presumed to involve the interdiffusion of chains across the cut as $\mathrm{NaCl}$ is able to break interpolymer crosslinks, providing the required mobility. In contrast, in the absence of $\mathrm{NaCl}$, polymer mobility is very low, and interchain crosslinks remain intact, making healing impossible. The lower salt concentrations required for healing in the PAA/P-EtP networks compared to the analogous ammonium networks ${ }^{14}$ likely results from the weaker ionic bonding between the phosphonium and carboxylate ions than between the ammonium and carboxylate ions in the PAA/PAH networks. This may be attributed to the more stericallyhindered nature of the quaternary phosphonium compared to the primary ammonium and to the lower charge density on the larger phosphonium ion.

\section{Conclusions}

New ionic networks based on PAA and polyphosphonium cations were investigated as selfhealing materials. While the P-Bu-P networks exhibited predominantly fluid-like behavior and very poor mechanical properties, P-Et-P networks exhibited viscoelastic behaviour that could be tuned according to their method of preparation and consequently the ratio of PAA to P-Et-P in the networks. PAA >P-Et-P, which was prepared by the addition of P-Et-P to a solution of PAA, 
had an intermediate tensile strength and Young's modulus and the highest elongation at break among the three studied networks, but most importantly exhibited sufficient dynamic behavior, with a relaxation time on the order of $\sim 30 \mathrm{~s}$, to be suitable for self-healing. Studies in $0.1 \mathrm{M}$ $\mathrm{NaCl}$ demonstrated that PAA $>$ P-Et-P could heal, whereas the PAA $\approx$ P-Et-P and PAA $<$ P-Et-P networks, which had predominantly elastic behavior, did not heal well. PAA $>$ P-Et-P did not heal in pure water, confirming that the presence of salt is necessary for the dynamic exchange of crosslinks in the healing mechanism. Tensile testing on healed networks showed that they were able to recover a significant fraction of their strength, modulus, and elongation, though further improvements would be desirable through tuning of the chemical structure of the polymers and in turn their rheology or by optimizing the healing conditions. These phosphonium networks exhibit mechanical properties and healing behaviour significantly different from the PAA/PAH networks studied previously. Most notably, the present materials undergo self-healing at salt concentrations similar to those encountered in physiological conditions. This makes phosphonium ionic networks of particular interest for biomedical applications. Future work will explore the potential for tuning the mechanical properties and healing behaviour of the networks by changing the chemical structures of the polymers such as by decreasing the steric bulk around the phosphonium centre using a trimethylphosphonium analogue or by changing the polyanion.

\section{Supporting Information}

NMR spectra, TGA and DSC data, SEC traces, calculations of network phosphorus content, additional tensile and self-healing data.

\section{Acknowledgements}


We thank the Natural Sciences and Engineering Council of Canada and The University of Western Ontario for funding this work and Solvay-Cytec for supplying starting materials.

\section{References}

(1) An, S. Y.; Arunbabu, D.; Noh, S. M.; Song, Y. K.; Oh, J. K. Recent Strategies to Develop Self-Healable Crosslinked Polymeric Networks. Chem. Commun. 2015, 51, 13058-13070.

(2) Bekas, D. G.; Tsirka, K.; Baltzis, D.; Paipetis, A. S. Self-Healing Materials: A Review of Advances in Materials, Evaluation, Characterization and Monitoring Techniques. Compos. Part B Eng. 2016, 87, 92-119.

(3) Wu, D. Y.; Meure, S.; Solomon, D. Self-Healing Polymeric Materials: A Review of Recent Developments. Prog. Polym. Sci. 2008, 33, 479-522.

(4) Yang, Y.; Urban, M. W. Self-Healing Polymeric Materials. Chem. Soc. Rev. 2013, 42, $7446-7467$.

(5) Ghosh, S. K. Self-Healing Materials: Fundamentals, Design Strategies, and Applications; Ghosh, S. K., Ed.; Wiley-VCH Verlag GmbH \& Co. KGaA: Weinheim, 2009.

(6) Wang, C.; Wu, H.; Chen, Z.; McDowell, M. T.; Cui, Y.; Bao, Z. Self-Healing Chemistry Enables the Stable Operation of Silicon Microparticle Anodes for High-Energy LithiumIon Batteries. Nat. Chem. 2013, 5, 1042-1048.

(7) Brochu, A. B. W.; Craig, S. L.; Reichert, W. M. Self-Healing Biomaterials. J. Biomed. Mater. Res., Part A 2011, 96 A, 492-506.

(8) Jacob, R. S.; Ghosh, D.; Singh, P. K.; Basu, S. K.; Jha, N. N.; Das, S.; Sukul, P. K.; Patil, S.; Sathaye, S.; Kumar, A.; Chowdhury, A.; Malik, S.; Sen, S.; Maji, S. K. Self Healing 
Hydrogels Composed of Amyloid Nano Fibrils for Cell Culture and Stem Cell Differentiation. Biomaterials 2015, 54, 97-105.

(9) Dailey, M. M. C.; Silvia, A. W.; McIntire, P. J.; Wilson, G. O.; Moore, J. S.; White, S. R. A Self-Healing Biomaterial Based on Free-Radical Polymerization. J. Biomed. Mater. Res., Part A 2014, 102, 3024-3032.

(10) White, S. R.; Sottos, N. R.; Geubelle, P. H.; Moore, J. S.; Kessler, M. R.; Sriram, S. R.; Brown, E. N.; Viswanathan, S. Autonomic Healing of Polymer Composites. Nature 2001, 409, 794-797.

(11) Toohey, K. S.; Sottos, N. R.; Lewis, J. A.; Moore, J. S.; White, S. R. Self-Healing Materials with Microvascular Networks. Nat. Mater. 2007, 6, 581-585.

(12) Chirila, T. V.; Lee, H. H.; Oddon, M.; Nieuwenhuizen, M. M. L.; Blakey, I.; Nicholson, T. M. Hydrogen-Bonded Supramolecular Polymers as Self-Healing Hydrogels: Effect of a Bulky Adamantyl Substituent in the Ureido-Pyrimidinone Monomer. J. Appl. Polym. Sci. 2014, 131, 1-12.

(13) Rao, Y.-L.; Chortos, A.; Pfattner, R.; Lissel, F.; Chiu, Y.-C.; Feig, V.; Xu, J.; Kurosawa, T.; Gu, X.; Wang, C.; He, M.; Chung, J. W.; Bao, Z. Stretchable Self-Healing Polymeric Dielectrics Cross-Linked Through Metal-Ligand Coordination. J. Am. Chem. Soc. 2016, $138,6020-6027$.

(14) Reisch, A.; Roger, E.; Phoeung, T.; Antheaume, C.; Orthlieb, C.; Boulmedais, F.; Lavalle, P.; Schlenoff, J. B.; Frisch, B.; Schaaf, P. On the Benefits of Rubbing Salt in the Cut: SelfHealing of Saloplastic PAA/PAH Compact Polyelectrolyte Complexes. Adv. Mater. 2014, $2547-2551$.

(15) Yoon, J. A.; Kamada, J.; Koynov, K.; Mohin, J.; Nicola, R.; Zhang, Y.; Balazs, A. C.; 
Kowalewski, T.; Matyjaszewski, K. Self-Healing Polymer Films Based on Thiol-Disulfide Exchange Reactions and Self-Healing Kinetics Measured Using Atomic Force Microscopy. Macromolecules 2012, 45, 142-149.

(16) Canadell, J.; Goossens, H.; Klumperman, B. Self-Healing Materials Based on Disulfide Links. Macromolecules 2011, 44, 2536-2541.

(17) Chen, X.; Dam, M. A.; Ono, K.; Mal, A. A Thermally Re-Mendable Cross-Linked Polymeric Material. Science 2002, 249, 115-118.

(18) Porcel, C. H.; Schlenoff, J. B. Compact Polyelectrolyte complexes: "Saloplastic" candidates for Biomaterials. Biomacromolecules 2009, 10, 2968-2975.

(19) Reisch, A.; Tirado, P.; Roger, E.; Boulmedais, F.; Collin, D.; Voegel, J. C.; Frisch, B.; Schaaf, P.; Schlenoff, J. B. Compact Saloplastic Poly(Acrylic Acid)/Poly(Allylamine) Complexes: Kinetic Control Over Composition, Microstructure, and Mechanical Properties. Adv. Funct. Mater. 2013, 23, 673-682.

(20) Bucur, C. B.; Sui, Z.; Schlenoff, J. B. Ideal Mixing in Polyelectrolyte Complexes and Multilayers: Entropy Driven Assembly. J. Am. Chem. Soc. 2006, 128, 13690-13691.

(21) Schaaf, P.; Schlenoff, J. B. Saloplastics: Processing Compact Polyelectrolyte Complexes. Adv. Mater. 2015, 27, 2420-2432.

(22) Holbrey, J. D.; Rogers, R. D. In Ionic liquids in Synthesis; Wassercheid, P., Welton, T., Eds.; WILEY-VCH Verlags GmbH \& Co. KGaA: Weinheim, 2008; Vol. 1, p 41-55.

(23) Bradaric, C. J.; Downard, A.; Kennedy, C.; Robertson, A. J.; Zhou, Y. Industrial Preparation of Phosphonium Ionic Liquids. Green Chem. 2003, 5, 143-152.

(24) Cassity, C. G.; Mirjafari, A.; Mobarrez, N.; Strickland, K. J.; O’Brien, R. A.; Davis, J. H. Ionic Liquids of Superior Thermal Stability. Chem. Commun. 2013, 49, 7590. 
(25) Hemp, S. T.; Zhang, M.; Allen, M. H.; Cheng, S.; Moore, R. B.; Long, T. E. Comparing Ammonium and Phosphonium Polymerized Ionic Liquids: Thermal Analysis, Conductivity, and Morphology. Macromol. Chem. Phys. 2013, 214, 2099-2107.

(26) Hemp, S. T.; Smith, A. E.; Bryson, J. M.; Allen, M. H.; Long, T. E. PhosphoniumContaining Diblock Copolymers for Enhanced Colloidal Stability and Efficient Nucleic Acid Delivery. Biomacromolecules 2012, 13, 2439-2445.

(27) Jangu, C.; Long, T. E. Phosphonium Cation-Containing Polymers: From Ionic Liquids to Polyelectrolytes. Polymer 2014, 55, 3298-3304.

(28) Kanazawa, A.; Ikeda, T.; Endo, T. Novel Polycationic Biocides: Synthesis and Antibacterial Activity of Polymeric Phosphonium Salts. J. Polym. Sci., Part A: Polym. Chem. 1993, 31, 335-343.

(29) Cuthbert, T. J.; Harrison, T. D.; Ragogna, P. J.; Gillies, E. R. Synthesis, Properties, and Antibacterial Activity of Polyphosphonium Semi-Interpenetrating Networks. J. Mater. Chem. B 2016, 4, 4872-4883.

(30) Choi, S. Y.; Rodríguez, H.; Gunaratne, H. Q. N.; Puga, A. V.; Gilpin, D.; McGrath, S.; Vyle, J. S.; Tunney, M. M.; Rogers, R. D.; McNally, T. Dual Functional Ionic Liquids as Antimicrobials and Plasticisers for Medical Grade PVCs. RSC Adv. 2014, 4, 8567.

(31) Cuthbert, T.; Guterman, R.; Ragogna, P. J.; Gillies, E. R. Contact Active Antibacterial Phosphonium Coatings Cured with UV Light. J. Mater. Chem. B 2015, 3, 1474-1478.

(32) Hisey, B.; Ragogna, P. J.; Gillies, E. R. Phosphonium-Functionalized Polymer Micelles with Intrinsic Antibacterial Activity. Biomacromolecules 2017, 18, 914-923.

(33) Wathier, M.; Grinstaff, M. W. Synthesis and Properties of Supramolecular Ionic Networks. J. Am. Chem. Soc. 2008, 130, 9648-9649. 
(34) Lin, X.; Navailles, L.; Nallet, F.; Grinstaff, M. W. Influence of Phosphonium Alkyl Substituents on the Rheological and Thermal Properties of Phosphonium-PAA-Based Supramolecular Polymeric Assemblies. Macromolecules 2012, 45, 9500-9506.

(35) Godeau, G.; Navailles, L.; Nallet, F.; Lin, X.; McIntosh, T. J.; Grinstaff, M. W. From Brittle to Pliant Viscoelastic Materials with Solid State Linear Polyphosphonium Carboxylate Assemblies. Macromolecules 2012, 45, 2509-2513.

(36) Tennyson, E. G.; He, S.; Osti, N. C.; Perahia, D.; Smith, R. C. Luminescent Phosphonium Polyelectrolyte Prepared from a Diphosphine Chromophore: Synthesis, Photophysics, and Layer-by-Layer Assembly. J. Mater. Chem. 2010, 20, 7984.

(37) Tsenoglou, C. Molecular Weight Polydispersity Effects on the Viscoelasticity of Entangled Linear Polymers. Macromolecules 1991, 24, 1762-1767.

(38) Chen, D. T. N. N.; Wen, Q.; Janmey, P. A.; Crocker, J. C.; Yodh, A. G. Rheology of Soft Materials. Annu. Rev. Condens. Matter Phys. 2010, 1, 301-322.

(39) Lawrence, P. G.; Patil, P. S.; Leipzig, N. D.; Lapitsky, Y. Ionically Cross-Linked Polymer Networks for the Multiple-Month Release of Small Molecules. ACS Appl. Mater. Interfaces 2016, 8, 4323-4335.

(40) Akhtar, R.; Sherratt, M. J.; Cruickshank, J. K.; Derby, B. Characterizing the Elastic Properties of Tissues. Mater. Today 2011, 14, 96-105. 